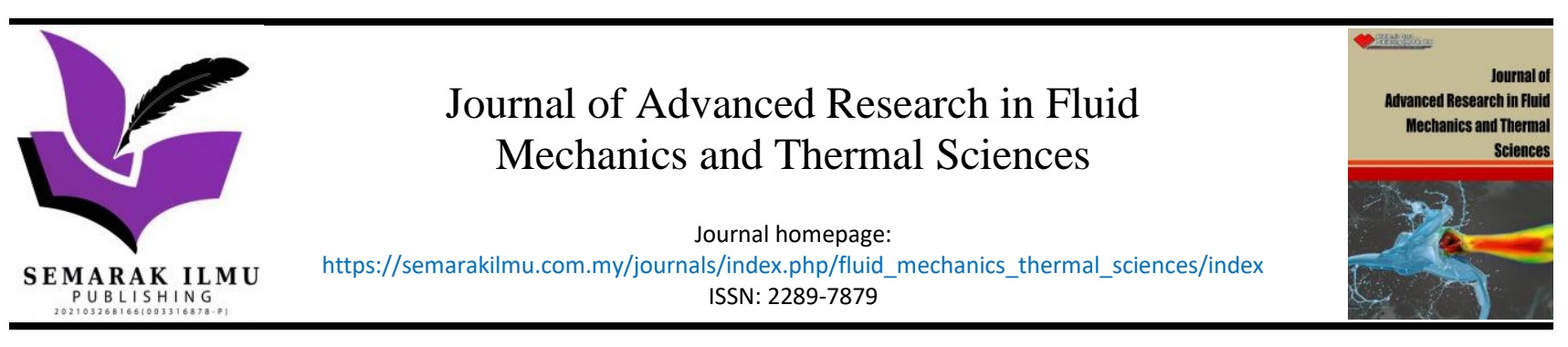

\title{
Optimization of Reaction Typed Water Turbine in Very Low Head Water Resources for Pico Hydro
}

\author{
Mohd Farriz Basar ${ }^{1,}{ }^{*}$, Nurul Ashikin M Rais ${ }^{1}$, Azhan Ab Rahman ${ }^{1}$, Wan Azani Mustafa ${ }^{2}$, \\ Kamaruzzaman Sopian ${ }^{3}$, Kaifui V. Wong ${ }^{4}$ \\ 1 Department of Electrical Engineering Technology, Faculty of Electrical and Electronic Engineering Technology, Universiti Teknikal Malaysia \\ Melaka (UTeM), Hang Tuah Jaya, 76100 Durian Tunggal, Melaka, Malaysia \\ 2 Faculty of Electrical Engineering Technology, Universiti Malaysia Perlis (UniMAP), Pauh Putra Campus, Arau, 02600, Malaysia \\ 3 Solar Energy Research Institute (SERI), Universiti Kebangsaan Malaysia, 43600 Bangi, Selangor, Malaysia \\ 4 Mechanical and Aerospace Department, University of Miami, Coral Gables, FL 33146, USA
}

\section{ARTICLE INFO}

Article history:

Received 18 August 2021

Received in revised form 9 November 2021

Accepted 11 November 2021

Available online 7 December 2021

\section{Keywords:}

Low flow; low head; pico-hydro; reaction turbine; Z-blade

\section{ABSTRACT}

\begin{abstract}
The purpose of this research is to investigate the dominant parameters that influence the optimum performance of reaction typed turbine at very low water head. The concepts of conservation of mass, momentum and energy are utilised to explore performance characteristics using a graphical technique. Parametric analysis of the governing equation and experimental results were performed to show that the turbine diameter and nozzle exit area has a dynamic response to mass flow rate, angular speed, output power and efficiency. Depending on the nozzle diameter of $(0.01 \mathrm{~m}, 0.006 \mathrm{~m}$, and $0.008 \mathrm{~m})$ and turbine pipe size with (diameter of $0.025 \mathrm{~m}$ and $0.015 \mathrm{~m}$ ), six versions of prototype turbine Z-blade turbine were produced. All the turbines have been tested at $100 \mathrm{kPa}$ static water pressures and below. According to a variety of experimental data for all types of turbines, the turbine diameter and nozzle exit area have a substantial impact on turbine performance, especially at high water heads. Despite differences in turbine length and nozzle exit area, more than $90 \%$ of the pattern curves for rotational speed, water flow rate, and mechanical power were identical. Overall, the Z-blade turbine Type $B$ outperforms, resulting in higher turbine efficiency at low head and low flow water condition.
\end{abstract}

\section{Introduction}

The most important principle for the hydro turbine is a rotating machine which converts potential water energy into kinetic and mechanical energy as well as electrical energy [1-3]. Over the centuries, there have been many different water turbines technologies developed, each operates with different principles [4]. For a water pump, electrical power is fed to drive the blades to collect water. In contrast, for a hydraulic turbine, the water drives the blades to rotate and finally produce electrical energy [5].

\footnotetext{
* Corresponding author.

E-mail address: mfarriz@utem.edu.my
}

https://doi.org/10.37934/arfmts.90.1.2339 
Water turbines are classified as impulse or reaction turbines based on their operation [6-8]. For impulse turbine, the water jet directed by the nozzle that hits the turbine blades will cause them to revolve [9-11]. The stationary nozzle on the other hand converts the water's potential energy (pressure) into kinetic energy [12-14]. This high-velocity stream's kinetic energy will then directly hit the blades. During this time, the water jet's pressure and size remain constant. Meanwhile, the direction of the water jet flow changes when it hits the blade. Furthermore, the bucket movement also reduces the absolute stream velocity [15-17].

For a pure reaction hydraulic turbine, it uses pressurised water to rotate the moving blades or nozzle [18-20]. The water flow velocity increases as it glides between the rotating blades, thus reducing the pressure. The pressure develops from the potential energy as well as the centrifugal head due to the self-pumping effect of the turbine [9]. The water sprinkling system is an example of a reaction turbine where the rotor rotates in the opposite direction of the water jet.

In the last decades, Hero's and Barker's mill turbine have been acknowledged worldwide as the prominent source of inspiration for the evolution of simple reaction turbines [16]. Later, both turbines were further refined to produce many other different types of turbines, such as Pupil's turbine, Whitlaw's mill, Quek's turbine and the Cross-pipe turbine (CPT). However, it was found later that the results of their performance were quite unsatisfactory. Furthermore, they were not suitable for applications in certain condition and water sites. At one time, this type of turbine was even declared to be inefficient and uncontrollable, hence continued to be ignored.

The development of a Z-blade reaction type turbine will be the topic of the following section. The experimental water test rig is described in Section 3 and it models near-real conditions for use at actual hydro sites. Next, the governing equations used to determine turbine performance are discussed in Section 4. Finally, the turbine's performance in very low-head applications is evaluated and analysed in Section 5.

This research also examines the performance of a test unit in ideal and actual conditions for different nominal PVC pipe diameters used in the turbine. The optimum turbine diameter and maximum rotating speed are anticipated and discussed. Based on the experimental results, the optimum turbine diameter was evaluated in relation to turbine mass flow rate, water head as well as rotor angular velocity. This paper also addresses the experimental data-driven performance curves of an innovative turbine. In terms of novelty, this research work tries to implement a turbine which are geometrically simple, easy to produce and inexpensive. Additionally, it is able to produce significant output at a high level of efficiency albeit sourced from a relatively low flow and low head water conditions. Hence, there is no need for big stream of river but instead even a small source of flowing water is more than adequate for the turbine to function well.

\section{Development of Z-blade Water Turbine}

It was discovered that CPT had numerous limitations and was inadequate for producing electrical power efficiently at low head hydro sites [15]. Due to the fixed size of standard galvanised steel pipe fittings, some of the constraints of CPT were related to the turbine diameter and nozzle exit area [19]. Additionally, the CPT prototype turns rather slowly and as a result, inefficiently at low head water levels, particularly for larger diameter turbines. It consumes considerable energy during operation, which is mostly due to the design of the V-ring lip seal. The efficiency is relatively low, ranging between $54 \%$ and $56 \%$ [16]. Due to these several drawbacks CPT manufacture was discontinued and there was no evidence of recent research on the CPT [5].

Taking cue from the limitations of CPT, a new type of turbine called Z-blade as shown in Figure 1 was developed. To design the Z-blade to work effectively in very low-head water conditions, 
significant adjustments to the CPT design were made. Instead of galvanized iron (GI) pipe, this innovative Z-blade turbine uses standard grey Class D PVC pipe fittings. When compared to GI pipes, the PVC pipe is inexpensive, readily available in local hardware stores and can be easily modified or adjusted to suit a significantly small-sized turbine diameter [7]. The Z-blade turbine is found to be more cost effective, with a total cost of USD 76. This is nearly half that of the CPT, which costs around USD 151. Due to the relatively simple fabricating process, the duration of turbine manufacturing is shorter and therefore accounts for a cheaper production cost. The most expensive part is the water coupling as shown Figure 1, and this is the only part that needs to be customised accordingly. The assembly process is also easy to perform, requiring no advanced technical expertise, skilled workers, or high-tech manufacturing machinery.

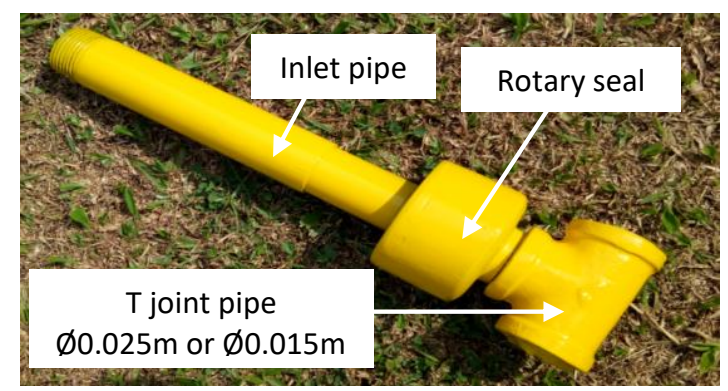

Fig. 1. Turbine coupling: rotary seal

This turbine has four major parts, as shown in Figure 2 and Figure 3: (a) one unit of a central Tjoint pipe, (b) two units of arms of male threaded PVC adapter fittings with different lengths of PVC pipes; (c) two $90^{\circ}$ PVC cooling units and (d) 2 PVC end cap units.

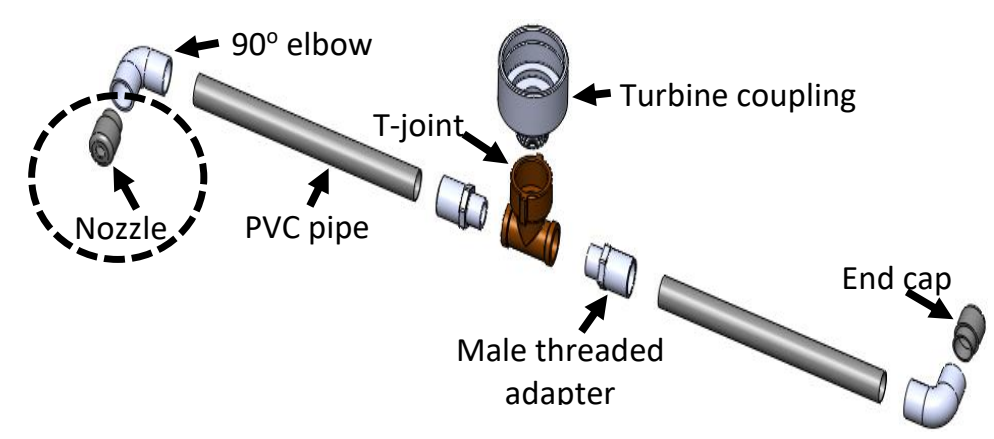

Fig. 2. Components of Z-blade

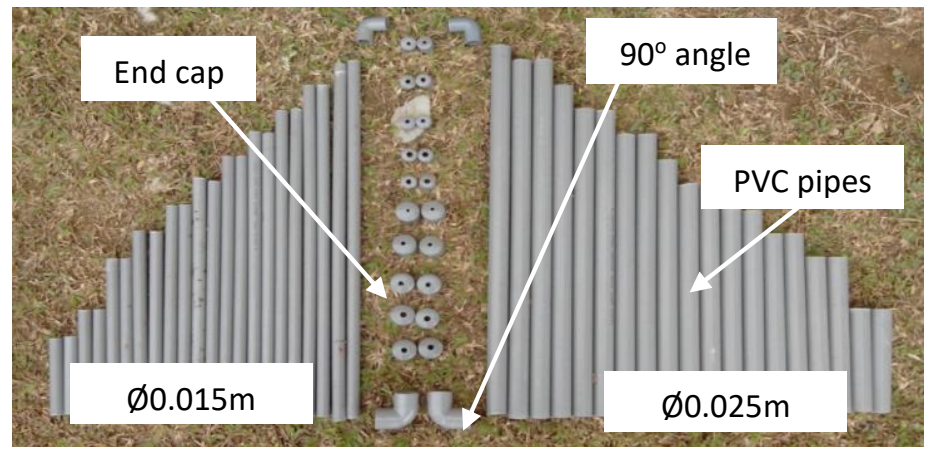

Fig. 3. End cap, $P V C$ pipe and $90^{\circ}$ elbow of Z-blade 
The nozzle exit area for the water jet is produced with a small hole in the centre of the PVC end cap with a different diameter. Hence, at the exit of both elbows, spray nozzles used in the CPT are not needed. The Z-blade also shows better features than the CPT because it does not have a fixed nozzle area dimension. This allows easy adjustment and modification of the nozzle exit range.

Table 1 provides a list of criteria for types A, B, C, D, E and F. Z-blade was further divided into six different types with different dimensions. It depends on the size of pipe (diameter $\varnothing 0.025 \mathrm{~m}$ : 1 inch or diameter $\varnothing 0.015 \mathrm{~m}: 0.5 \mathrm{inch}$ ), and the size of nozzle used. As shown in Table 1, the radius of nozzle exit area is set at $0.003 \mathrm{~m}\left(A=0.0000565 \mathrm{~m}^{2}\right), 0.004 \mathrm{~m}\left(A=0.0001 \mathrm{~m}^{2}\right)$ and $0.005 \mathrm{~m}\left(A=0.000157 \mathrm{~m}^{2}\right)$. With this arrangement, the optimum performance of Z-blade can be identified by comparing the results of each type of turbine.

Table 1

Six types of Z-blade turbine

\begin{tabular}{lll}
\hline Type & Size of pipe & Nozzle diameter \\
\hline A & $\varnothing 0.025 \mathrm{m:}: 1.0$ inch & $0.010 \mathrm{~m}$ \\
B & $\varnothing 0.025 \mathrm{m:}: 1.0$ inch & $0.008 \mathrm{~m}$ \\
C & $\varnothing 0.025 \mathrm{~m}: 1.0$ inch & $0.006 \mathrm{~m}$ \\
D & $\varnothing 0.015 \mathrm{m:}: 0.5$ inch & $0.010 \mathrm{~m}$ \\
E & $\varnothing 0.015 \mathrm{m:}: 0.5$ inch & $0.008 \mathrm{~m}$ \\
F & $\varnothing 0.015 \mathrm{m:} 0.5$ inch & $0.006 \mathrm{~m}$ \\
\hline
\end{tabular}

Besides that, according to Figure 4, the turbine diameter $D_{T}$ in this research work is varied from $0.35 \mathrm{~m}$ to $1.7 \mathrm{~m}$. It is to be noted that due to the fixed dimensions of the standard PVC pipe fitting of the $\varnothing 0.025 \mathrm{~m}: 1$ inch and $\varnothing 0.015 \mathrm{~m}$ : 0.5-inch pipe, the turbine diameter cannot be reduced below $0.35 \mathrm{~m}$, even while using the shortest possible standard pipe fittings. Furthermore, the length of the arm of the turbine should not be longer than $1.7 \mathrm{~m}$. The reason for this is that the performance will be less significant and considerably low according to the theoretical analysis when the turbine diameter is $1.5 \mathrm{~m}$ or above in length. In addition, the $\varnothing 0.025 \mathrm{~m}: 1$ inch and $\varnothing 0.015 \mathrm{~m}$ : 0.5-inch PVC pipes are widely used, readily available and inexpensive. Enlarged pipe widths will also increase water flow rate across the Z-blade, undermining the aim of investigating turbine performance in low flow water conditions. As for the nozzle diameter, prior trial and error experiment was carried out and it was found that the $0.008 \mathrm{~m}$ diameter produced the best performance. The $0.006 \mathrm{~m}$ and $0.01 \mathrm{~m}$ data were merely included for comparison.

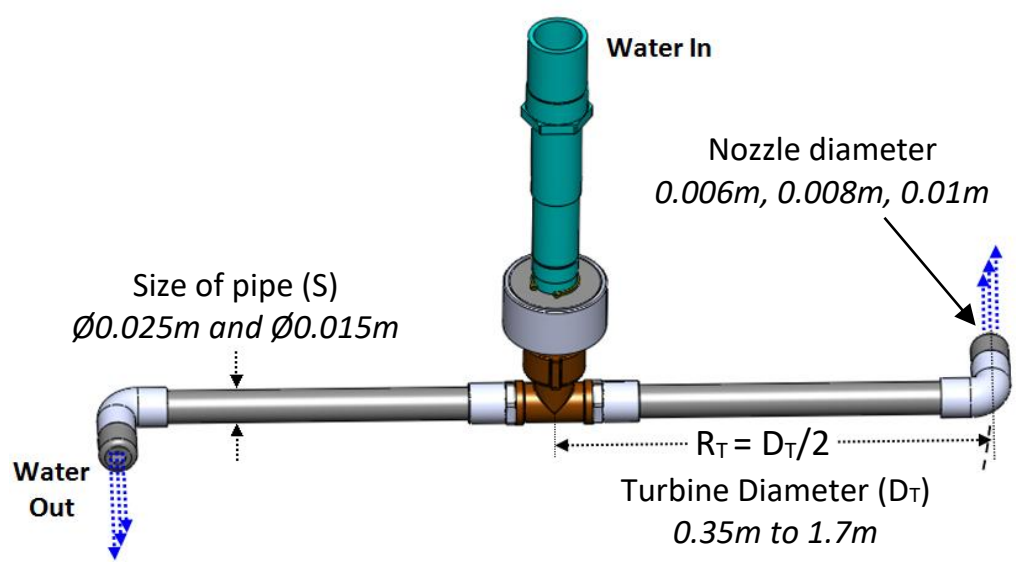

Fig. 4. Dimension of the Z-blade turbine 


\section{Water Test Rig}

To a certain extent, the research has developed an improved and more effective experimental setup which is easy to assemble and resembles the hydro sites near-real condition. The Z-blade turbine is tested by feeding water from the top of the blade and installing the generator at the bottom. This project uses a Golden Motor 902-36V-24R-902 permanent magnet generator with a 36 $\mathrm{V}$ rated voltage and $250 \mathrm{~W}$ output. In many renewable energy projects, this low friction generator has proven to be quite effective in generating electricity and charging batteries [5]. According to comparative study conducted by Yaakub et al., [2], this permanent magnet generator is the most suited for stand-alone hydro plants.

As illustrated in Figure 5, this arrangement fully utilises the gravitational potential energy supplied by the water tank. The test rig can produce a water head of up to $5 \mathrm{~m}$ and a mass water flow rate of up to $2.5 \mathrm{~L} / \mathrm{s}$. As a result, this experimental arrangement is appropriate for either a run-off-river or a run-on-river method. Both methods use upstream intake water piped to a downstream hydro system. Run-on-river hydro systems are installed and operated within the river, whereas run-of-river hydro systems are installed and operated at the riverbank [1].

It is assumed that at real-world sites, the water tank will be filled with river water and the water exiting the turbine nozzle will be redirected into the river [5]. During such operation, the Z-blade turbine rotates clockwise when the fluid exits the nozzle tangentially, inducing a reaction force and causing movement of the rotor in the reverse direction of the water jet thus, simultaneously producing mechanical and electrical power.

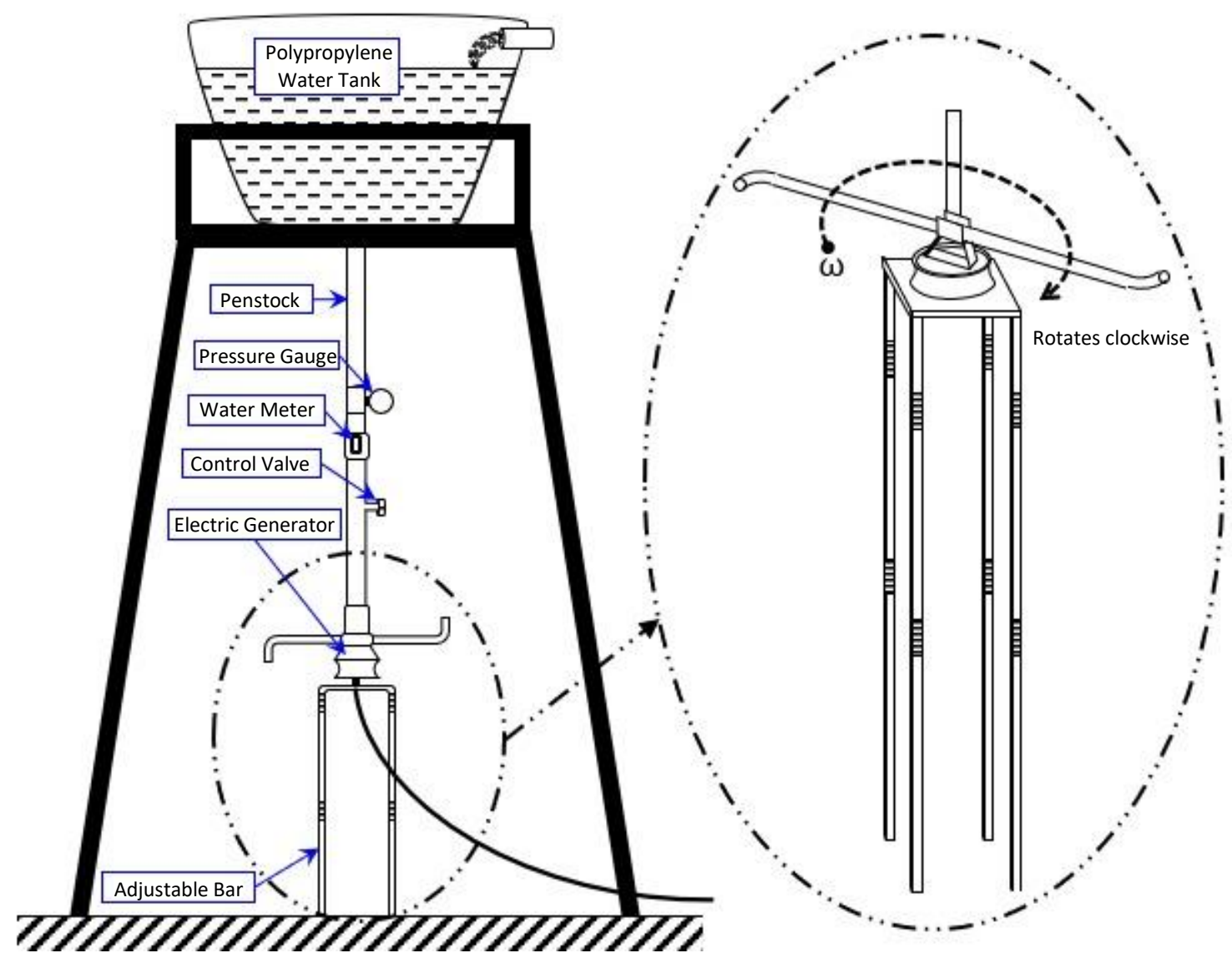

Fig. 5. Schematic of water test rig 


\section{Parametric Study via Governing Equations}

The performance of the Z-blade has been predicted and analyzed using the governing equations which were developed from the fundamental principles of conservation of mass, momentum, and energy [15]. These principles rely on several following assumptions done by Date [9]

i. Constant water density.

ii. Inability of energy to be dissipated through viscosity.

iii. Any liquid fluid flow loss of the tank (storage) through the piping system is not considered.

iv. Any mechanical losses such as loss of wind caused by turbine rotation shall not be considered.

v. Inconsideration for any frictional losses of the pipe coupling.

Figure 6 displays the parameters for ideal and practical condition analysis in evaluating the performance of the Z-blade. The effect on the performance of Z-blade were examined for the prevailing parameters such as mass flow rate, optimal diameter of the turbine, rotational speed and relative velocity for different working water heads and different PVC pipe diameters.

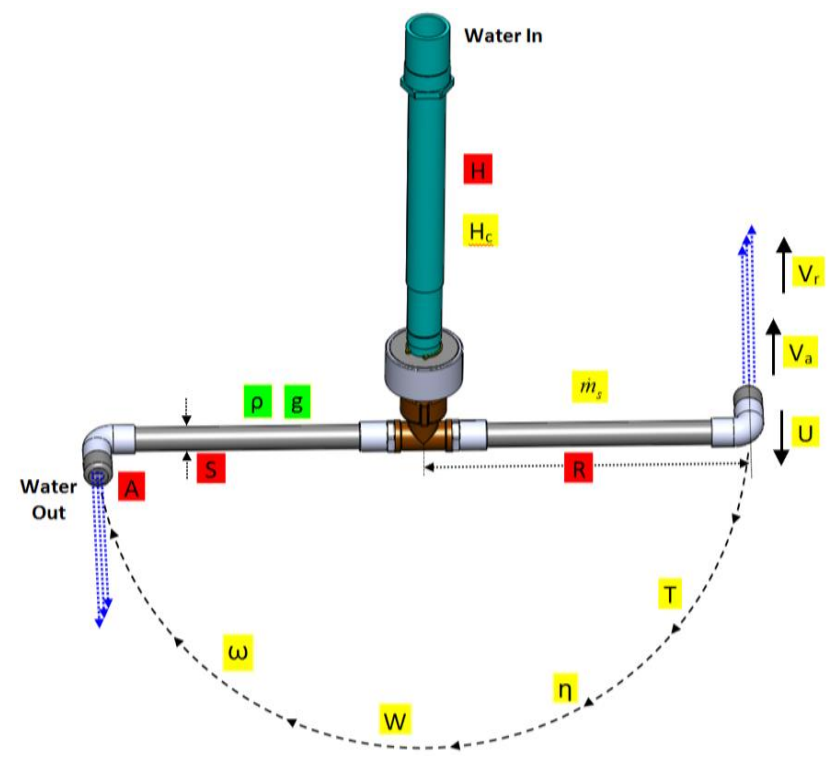

Fig. 6. Rotor stationary reference frame

$$
\begin{aligned}
& \dot{m} g H=\dot{W}+\frac{1}{2} \dot{m} V_{a}^{2} \\
& U=R \omega \\
& V_{a}=V_{r}-U \\
& V_{a}=V_{r}-R \omega
\end{aligned}
$$

where $U$ is tangential velocity of the nozzles, $V_{a}$ is absolute velocity of water leaving nozzle with respect to a stationary, $H$ is water height and $R$ is radius of the rotor. Ideally, the kinetic energy is, 


$$
\frac{1}{2} \rho V_{r}^{2}=\rho g\left(H+H_{c}\right)
$$

The centrifugal head $H_{c}$ which exist during the turbine rotation is,

$$
H_{c}=\frac{U^{2}}{2 g}=\frac{R^{2} \omega^{2}}{2 g}
$$

The combination of Eq. (5) and Eq. (6) leads to relative velocity $V_{r}$ of water with respect to the nozzle,

$$
V_{r}=\sqrt{2 g H+R^{2} \omega^{2}}
$$

The mass flow rate, $\dot{m}$ released into the atmosphere by the nozzle can be expressed as

$$
\dot{m}=\rho A V_{r}
$$

Therefore,

$$
\dot{m}=\rho A \sqrt{2 g H+R^{2} \omega^{2}}
$$

When the turbine is stationary, $\omega=0$, the mass flow rate is calculated as follows:

$$
\dot{m}_{S}=\rho A \sqrt{2 g H}
$$

By rewriting Eq. (9), the rotor's angular speed is,

$$
\omega=\frac{\sqrt{\left(\frac{\dot{m}}{\rho A}\right)^{2}-2 g H}}{R}
$$

Torque can be calculated,

$$
T=\dot{m} V_{a} R
$$

The turbine's mechanical output power, $\dot{W}$ is as follows:

$$
\dot{W}=T \omega
$$

The following equation can be used to determine the system's efficiency,

$$
\eta=\frac{\dot{W}}{\dot{m} g H}
$$




\section{Experimental Investigation}

This section describes the evaluation and analysis of Z-blade turbine's performance. Figure 7 to Figure 13 illustrate the theoretical and measured performance curves for the Z-blade reaction water turbine. The results for various water heads are reported, with an emphasis on the $10 \mathrm{~m}$ water head and below. This is the range of water heads more suited to simple reaction turbines [7-9]. In general, hydro sites with a water head of less than $10 \mathrm{~m}$ are the most suitable for pico-hydro turbines, as the ramifications of rivers, streams, waterfalls, and irrigation channels are plentiful in nature $[1,2]$.

\subsection{Performance of Z-blade Turbine}

This section focuses into the performance of the system as it relates to various turbine diameters. The diameter of the turbine is an important factor in generating high rotational speed and ensuring optimal performance. In Figure 7 and Figure 8, the dotted line depicts practical data acquired through laboratory work, which follows a similar pattern to the theoretical analysis but slightly less in magnitude. It was discovered that the measured performance curves pattern is comparable for both nominal pipe sizes. Thusly, the $0.025 \mathrm{~m}$ blade (Type B) performs significantly better than the $0.015 \mathrm{~m}$ blade (Type E). It is important to note that the ideal blade for $0.025 \mathrm{~m}$ is Type $\mathrm{B}$. Meanwhile, Type $\mathrm{E}$ is the best option for $0.015 \mathrm{~m}$ blades.

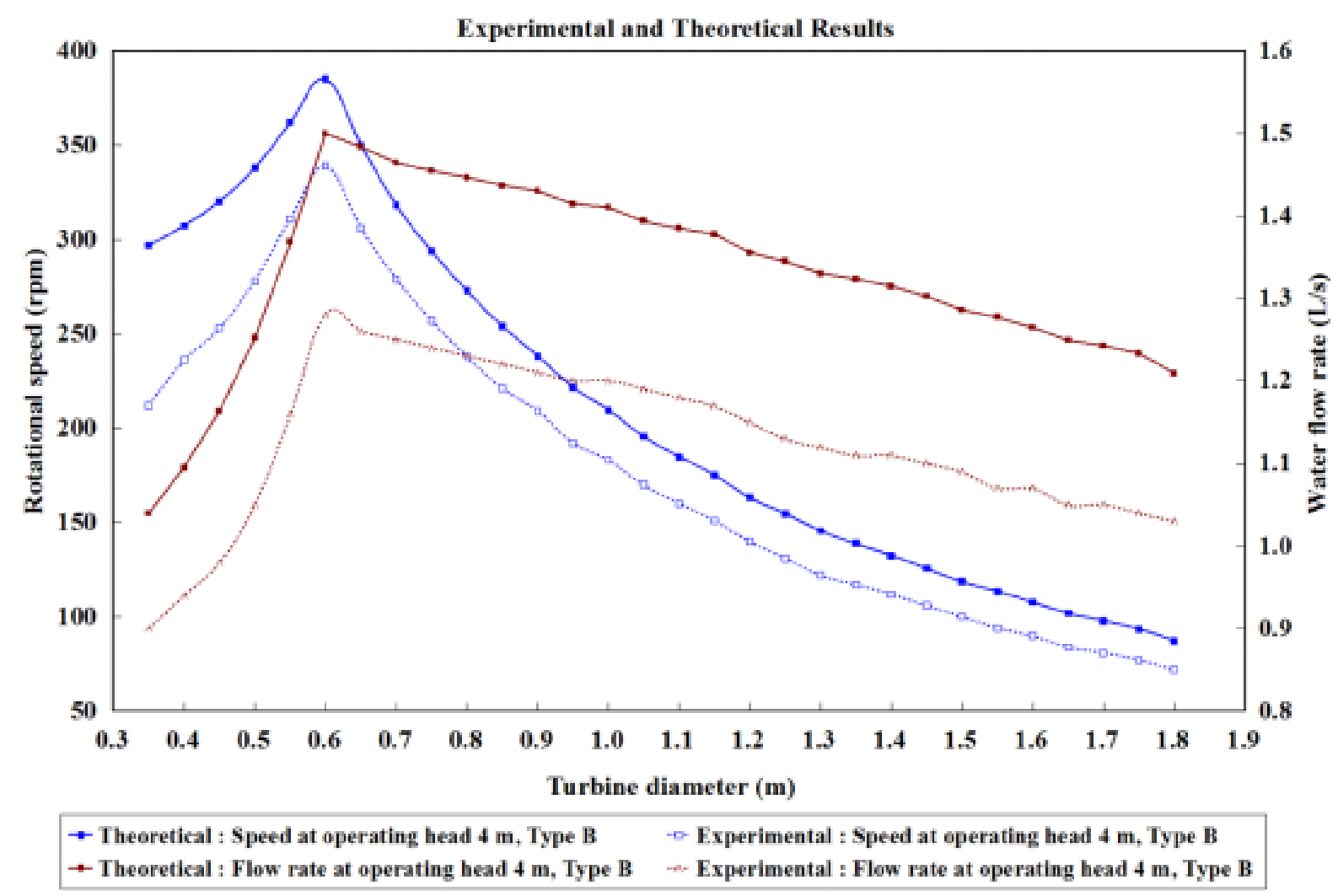

Fig. 7. Experimental and theoretical results for the $4 \mathrm{~m}$ static head (nominal diameter: $\varnothing 0.025 \mathrm{~m}$ ) 


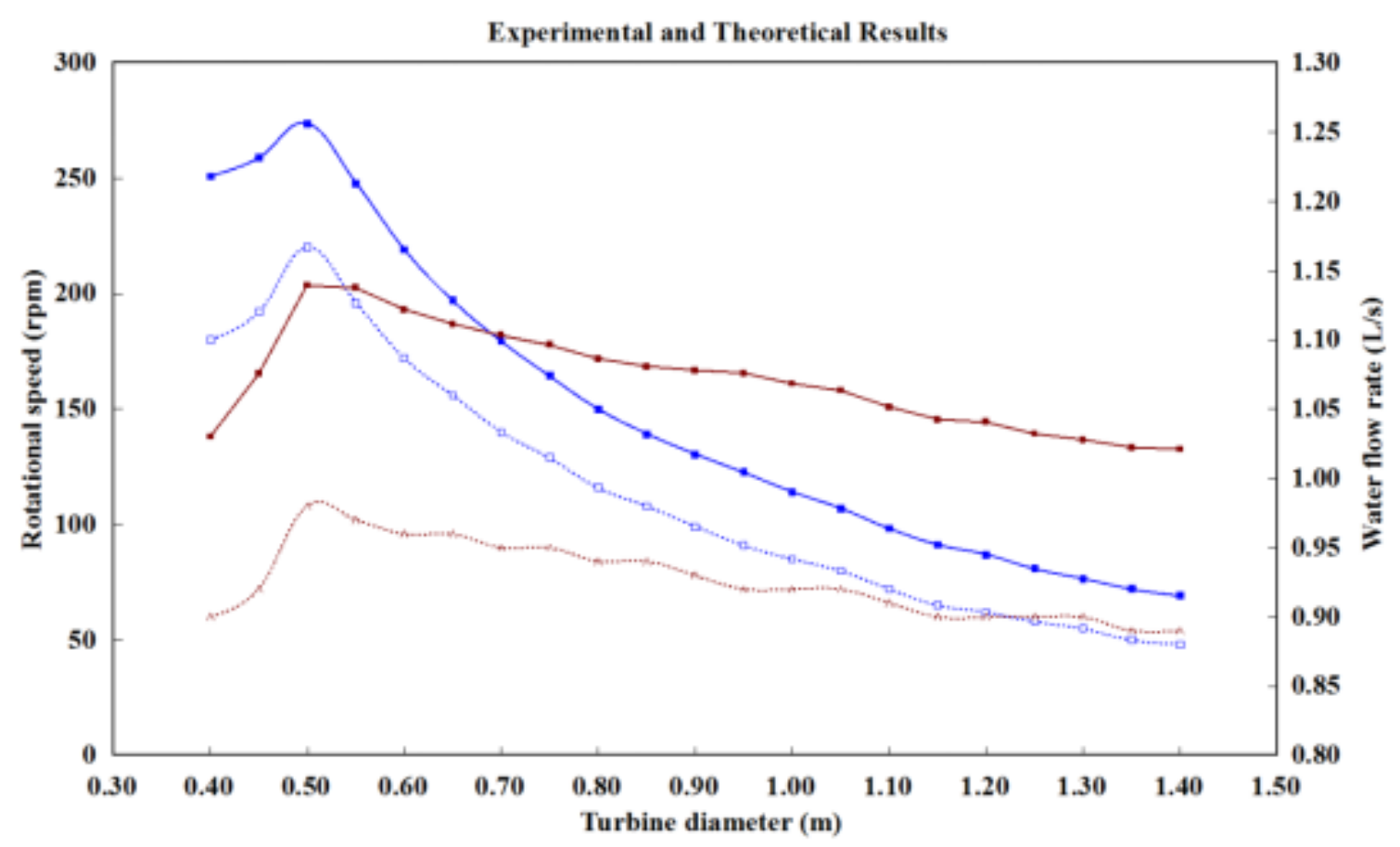

$$
\begin{aligned}
& \text { - Theoretical : Speed at operating head } 4 \mathrm{~m} \text {, Type E } \quad \text { Experimental : Speed at operating head } 4 \mathrm{~m}, \text { Type E } \\
& \rightarrow \text { Theoretical : Flow rate at operating head } 4 \mathrm{~m} \text {, Type E - Experimental : Flow rate at operating head } 4 \mathrm{~m} \text {, Type E }
\end{aligned}
$$

Fig. 8. Experimental and theoretical results for the $4 \mathrm{~m}$ static head (nominal diameter: $\varnothing$ $0.015 \mathrm{~m})$

By referring to Figure 7 and Figure 8 respectively, when the water head is fixed at $4 \mathrm{~m}$, the blade with nominal diameter of $0.025 \mathrm{~m}$ reached the maximum rotational speed slower when compared with the blade with nominal diameter of $0.015 \mathrm{~m}$. The former reached its maximum rotational speed when the turbine diameter is at $0.6 \mathrm{~m}$, whereas the latter reached its maximum rotational speed when the turbine diameter is at $0.5 \mathrm{~m}$. This finding indicates that the blade with $0.025 \mathrm{~m}$ nominal diameter requires $0.1 \mathrm{~m}$ longer turbine diameter to reach its maximum rotational speed as opposed to the blade with $0.015 \mathrm{~m}$ nominal diameter. Practically, the $0.015 \mathrm{~m}$ blade will reach a maximum speed of $225 \mathrm{rpm}$ when the flow rate reaches $0.98 \mathrm{~L} / \mathrm{s}$, and the turbine diameter is $0.5 \mathrm{~m}$. For the $0.025 \mathrm{~m}$ blade, the maximum speed of $339 \mathrm{rpm}$ is obtained when the flow rate reaches $1.28 \mathrm{~L} / \mathrm{s}$, and $0.6 \mathrm{~m}$ diameter turbines are used. Additionally, the magnitude of speed for the $0.015 \mathrm{~m}$ blade is approximately $33.6 \%$ lower than the maximum speed of the $0.025 \mathrm{~m}$ blade.

Initially, with the short turbine diameter, the difference in speed between theoretical and experimental results are found to be high. However, both speed curves approach each other towards the higher turbine diameter. Basically, for the short turbine diameter, its speed is found to be very sensitive to the mass flow rate since a minor change in mass flow rate can cause a great change to the rotational speed. The small value of radius of the rotor, $\mathrm{R}$ can also have a significant impact on the increase in speed value. Conversely, by referring to Eq. (11), towards the longer turbine diameter, the higher value of $\mathrm{R}$ causes the speed value to slowly reduce, thus approaching the constant speed.

In comparison to other reaction hydro turbines, the Z-blade turbine requires only low-head and low-flow water resources. Additionally, it is observed that the larger the nominal diameter of the PVC pipe, the greater the maximum rotational speed obtained because of the mass flow rate increment. Furthermore, when the PVC pipe size is increased, the length of the optimum turbine diameter that will be used will also be increased. The term "optimal diameter" refers to the unique rotor diameter that corresponds to the rotor's maximum angular speed at a constant operating head and constant PVC pipe size. As demonstrated in Figure 9, the turbine operates at a water flow rate of only $1.28 \mathrm{~L} / \mathrm{s}$ 
and a water head of $4 \mathrm{~m}$ to generate approximately $43.7 \mathrm{~W}$ of output power. The experimental results established that the Z-blade is capable of operating under low-head and low-flow conditions.

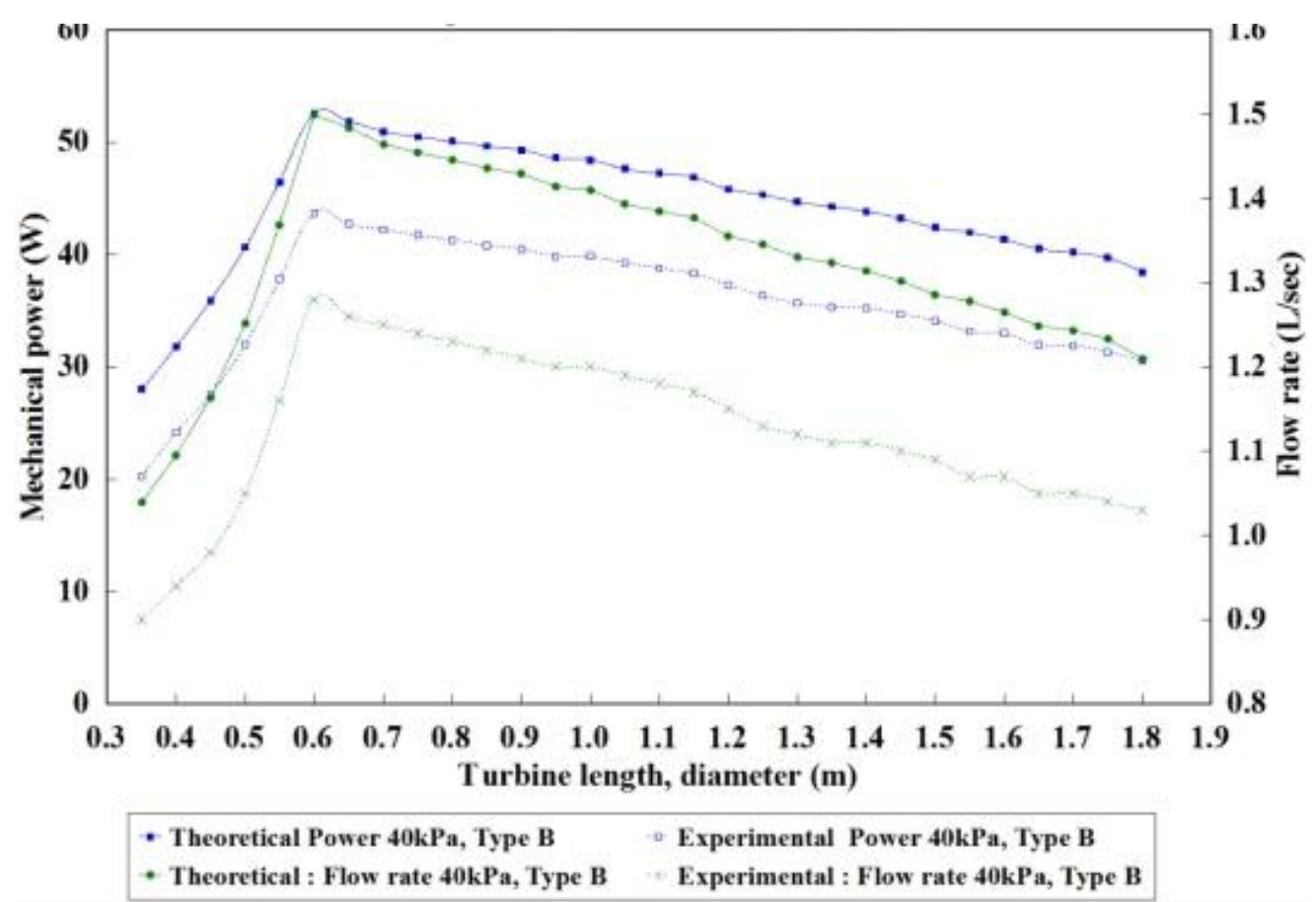

Fig. 9. Experimental and theoretical output power for the $4 \mathrm{~m}$ static head (nominal diameter: $\varnothing 0.025 \mathrm{~m})$

According to Figure 9, the theoretical output power curve is higher than the actual output power curve for various turbine diameters. Remarkably, the curve of power production is directly proportional to the curve of mass flow rate. The highest power output occurs at the optimal rotor diameter, which also happens at the maximum rotating speed. Moreover, the maximum power exists when the increment of mass flow rate varies. Once the maximum power is attained, the rate of increase in mechanical power begins to rapidly decrease.

\subsection{Performance Comparison of CPT and Z-blade Turbine}

The rotational speed for CPT and Z-blade turbine for various turbine diameters and operating heads are shown in Figure 10. The operational head, $\mathrm{H}$, varies from $3 \mathrm{~m} \mathrm{(30} \mathrm{kPa)} \mathrm{to} 5 \mathrm{~m} \mathrm{(50} \mathrm{kPa)} \mathrm{and}$ the comparison is made when the k-factors for CPT and Z-blade turbine are set at 0.05. The k-factor is a coefficient introduced by Date et al., [16] that represents the fluid frictional power loss associated with fluid flow through the turbine. It is critical to address this power loss since that some energy would be lost due to fluid friction, especially because of the high velocity of exiting water jets. The coefficient k-factor is related to relative velocity and has a considerable effect on both the absolute velocity and rotational speed components [19]. Due to the increased value of the k-factor, the Zblade's efficiency in converting potential energy to output power will be substantially lower than planned. 


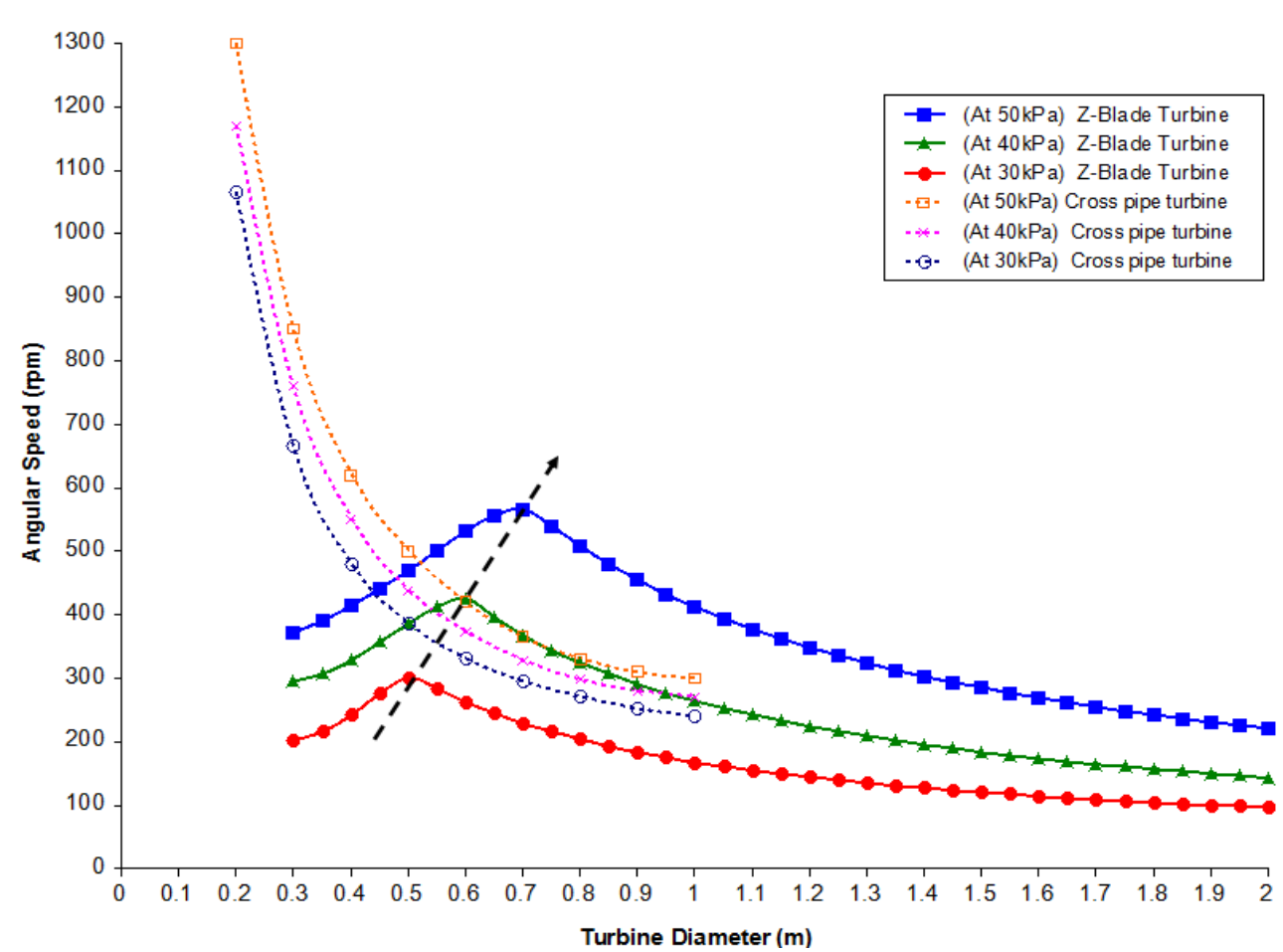

Fig. 10. Rotational speed versus turbine diameter for various operating heads adapted from data from Date's [9] study

The theoretical curve of the CPT turbine is adapted from Date's [9] study, where it was estimated using the governing equations discussed in [19]. The theoretical performance curves of the Z-blade turbine with pipe size $0.025 \mathrm{~m}$ were estimated using the governing equations discussed in section 4.0.

The rotational speed of the CPT turbine is high with a linear variation line when the rotor diameter is not large. This suggests that the CPT must be fabricated with a small diameter to obtain high angular speeds and high generation of mechanical power. Owing to the fixed dimensions of the standard $0.08 \mathrm{~m}$ ( 3 inch) pipe cross, it is difficult to fabricate the CPT with the diameter of less than $0.4 \mathrm{~m}$ [5]. However, the influence of the operating head on the rotational speeds is less significant at a higher turbine diameter. On the other hand, for a constant water head, the rotational speed reduces with an increase in the CPT turbine diameter.

Conversely, the rotational speed of the Z-blade turbine decreases in a bell-shaped curve as the turbine diameter increases. The peak point of the curve is defined for the maximum rotational speed corresponding to the optimum rotor diameter at a constant operating head. In addition, at a constant operating head, the highest rotor speed did not occur during the blade's small diameter. It is improbable that the highest rotor speed will be achieved by a simple reaction turbine such as a CPT, as it cannot be manufactured in small diameters.

The maximum rotational speed (peak point) and optimum turbine diameter increase when the water head is increased. By connecting all the peak points in every curve for all water heads, it forms a linear line that also indicates the optimum turbine diameter line. Furthermore, as operating head increases, this peak point tends to shift to the right area of the graph, increasing the value of the maximum angular speed and optimum turbine diameter. Moreover, when the rotor blades are focused toward a large diameter, the head's effect on rotational speed diminishes. 


\subsection{Optimum Turbine Diameter}

The nomogram illustration in Figure 11 can be used to select the optimum Z-blade turbine. The linear lines can provide information about the optimum turbine diameter as well as the maximum angular speed that the turbine can achieve. The information is gathered by simply providing the nominal diameter of the PVC pipe and the value of the operational water head.

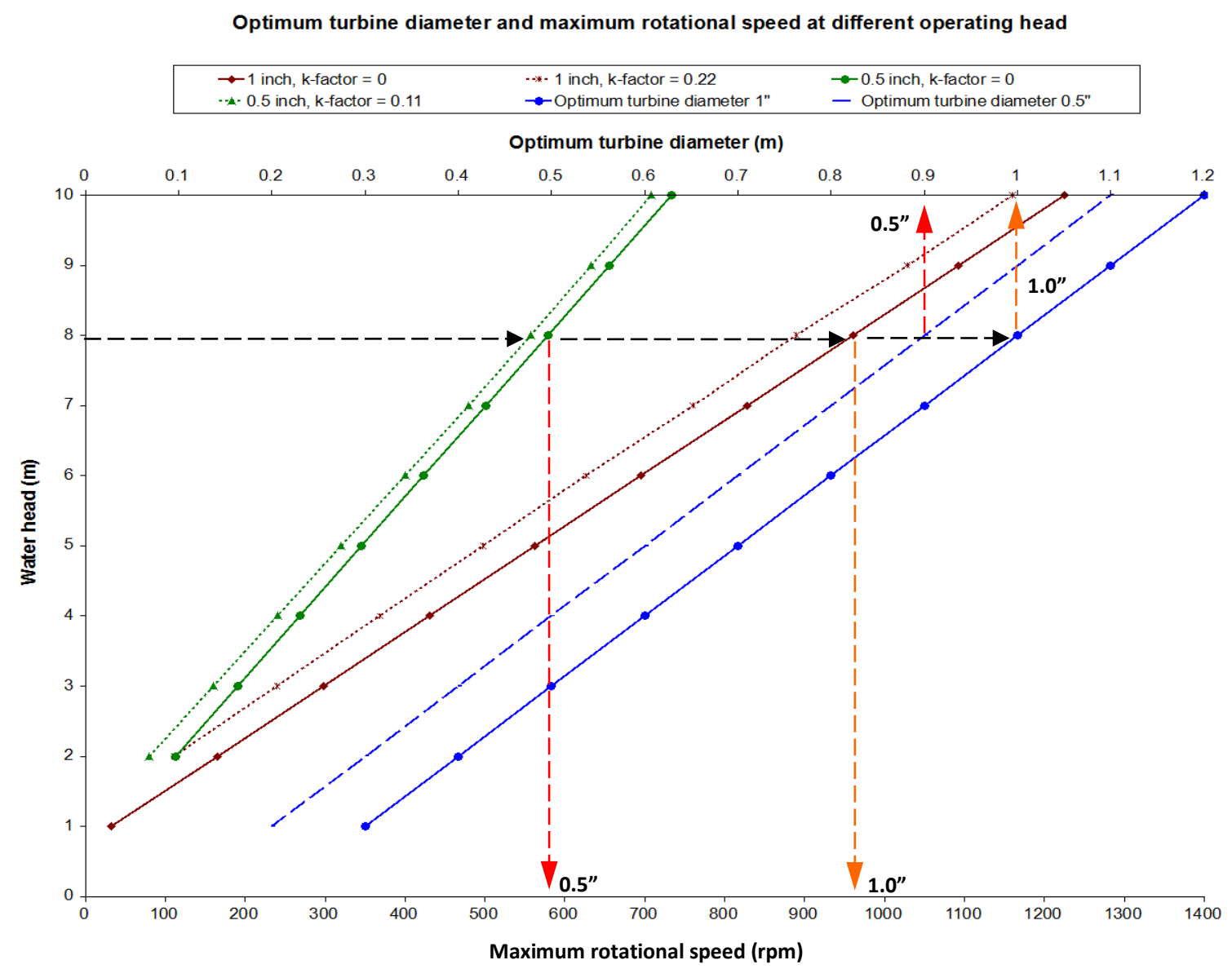

Fig. 11. Theoretical and experimental results of the optimum turbine diameter

According to Figure 11, if the available water head is $8 \mathrm{~m}$, the maximum rotational speed of the $0.015 \mathrm{~m}$ blade is $576 \mathrm{rpm}$, and the turbine diameter is estimated to be $0.9 \mathrm{~m}$. Likewise, if the water head is $8 \mathrm{~m}$, then for the $0.025 \mathrm{~m}$ blade, the maximum rotational speed is $960 \mathrm{rpm}$, and the turbine diameter is estimated at $1 \mathrm{~m}$. The rotational speed for the $0.025 \mathrm{~m}$ blade and $0.015 \mathrm{~m}$ blade with an ideal condition ( $\mathrm{k}$-factor $=0$ ) are consistently leading the other non-ideal lines towards the increment of the water head.

Furthermore, Figure 11 shows that the linear line of the optimum turbine diameter versus the water head for both nominal diameters of the PVC pipe. Additionally, the optimum turbine diameter for the theoretical and experimental value is found to be similar. It shows that the difference of water flow rate and angular speed in the theoretical and experimental values do not cause any difference in the optimum turbine diameter. 
Ideally, the Z-blade turbine with a $0.025 \mathrm{~m}$ blade is capable of rotating with a minimum static head equals to $1 \mathrm{~m}$ and the $0.015 \mathrm{~m}$ blade equals to $2 \mathrm{~m}$. However, if the k-factor for the $0.025 \mathrm{~m}$ blade is 0.22 , the water head required is at least $2 \mathrm{~m}$. As discussed by Date et al., [16], these turbines must exceed the stationary mass flow rate $\mathrm{m}_{\mathrm{s}}$ as defined in Eq. (10), to start the rotations. It clearly shows that, for an ideal case, only the $0.025 \mathrm{~m}$ blade has the mass flow rate exceeding $\mathrm{m}_{\mathrm{s}}$ needed at the $1 \mathrm{~m}$ water head. However, the $0.015 \mathrm{~m}$ blade can fulfil the $\mathrm{m}_{\mathrm{s}}$ condition when the water head is at $2 \mathrm{~m}$.

Overall, the optimum turbine diameter for the $0.015 \mathrm{~m}$ blade is only distinguished by the $0.1 \mathrm{~m}$ than the $0.025 \mathrm{~m}$ blade. However, it makes a huge difference in the rotor speed and finally the output power generated. For a constant water head, the $0.015 \mathrm{~m}$ blade rotates slower than the speed generated by the $0.025 \mathrm{~m}$ blade. The low rotational speed causes a lower centrifugal pumping head produced by the turbine and leads the mass flow rate through the $0.015 \mathrm{~m}$ blade, lesser than the $0.025 \mathrm{~m}$ blade. Hence, the lower output power (W) is produced by the $0.015 \mathrm{~m}$ blade due to the reduction in the water flow rate $(m)$, rotational speed $(\omega)$, relative velocity $\left(V_{r}\right)$, and optimum turbine diameter.

\subsection{Effect of Nozzle Exit Area on Turbine Performance}

Figure 12 and Figure 13 show the variation of experimental result for all type of turbine for 50 $\mathrm{kPa}(\approx 5 \mathrm{~m})$ and $40 \mathrm{kPa}(\approx 4 \mathrm{~m})$ static water head. In general, the nozzle exit area has a significant impact on turbine performance, especially at high water head. Even though the nozzle exit is varied, the curve patterns for the rotational speed, water flow rate, mechanical power, and efficiency were similar except for the magnitude.

Overall, a nozzle diameter of $0.008 \mathrm{~m}$ yields better performance compared to other nozzle diameters. In particular, the nozzle at this size resulted in higher rotational speeds, mechanical power, and efficiency whereas, it only requires a small volume of water. Besides that, the closest competitor of nozzle diameter of $0.008 \mathrm{~m}$ (Type $\mathrm{B}$ and Type $\mathrm{E}$ ) is nozzle diameter of $0.006 \mathrm{~m}$ (Type $\mathrm{C}$ and Type F). As an example, at $5 \mathrm{~m}$ water head, turbine Type $C$ rotates at a speed nearly like the rotation of turbine Type $B$ and it requires much less volume of water at about $1.0 \mathrm{~L} / \mathrm{s}$. Meanwhile, turbine Type $B$ requires a slightly higher water volume than by Type $C$ at about $1.8 \mathrm{~L} / \mathrm{s}$. However, compared to Type C, Type B shows better performance in terms of mechanical output power and efficiency. This is the reasons that Type $B$ for $\varnothing 0.025 \mathrm{~m}: 1$ inch blade is chosen as the optimum type of turbine particularly for $5 \mathrm{~m}$ and $4 \mathrm{~m}$ water head. In addition, the nozzle with a diameter of 0.008 $\mathrm{m}$ also yields optimum performance for the turbine developed from $\varnothing 0.015 \mathrm{~m}$ : 0.5 -inch blade, which is of Type $E$.

For all nozzle sizes, with increasing water head, the system was able to convert the potential energy into work with much higher output and efficiency. Furthermore, the mechanical power also increases towards higher water head. According to Figure 12 and Figure 13, Type A shows the lowest performance, followed by Type $\mathrm{C}$ and the highest efficiency is Type $\mathrm{B}$. Indirectly, it indicates that, for any size of PVC pipe, the nozzle diameter is highly influential in determining the overall performance, particularly on the mechanical output power and system efficiency. In this case, the optimum turbine is a blade with nozzle diameter with $0.008 \mathrm{~m}$, followed by $0.006 \mathrm{~m}$ and $0.01 \mathrm{~m}$. 


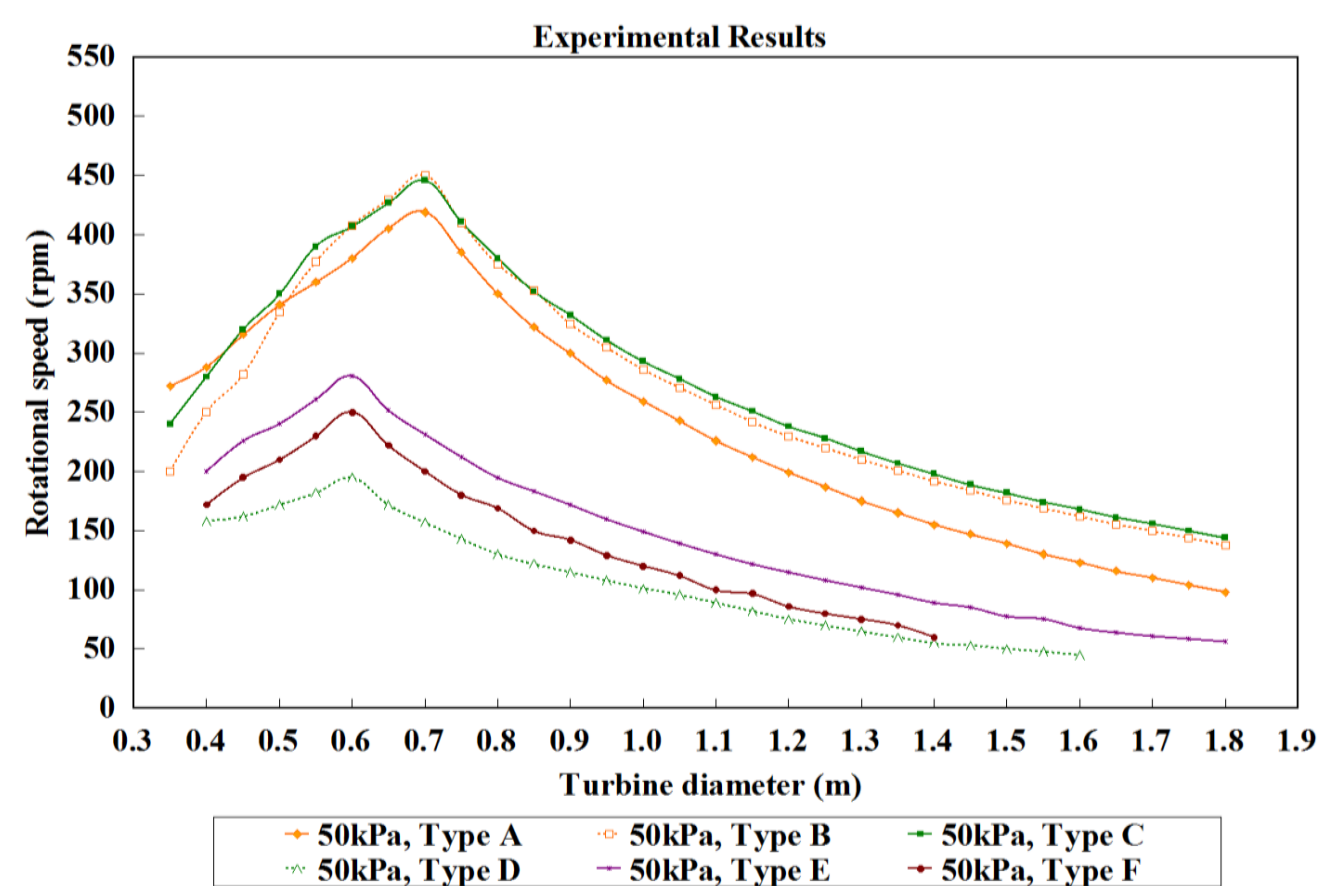

Fig. 12. Rotational speed for various types of Z-blade at $5 \mathrm{~m}$ water head

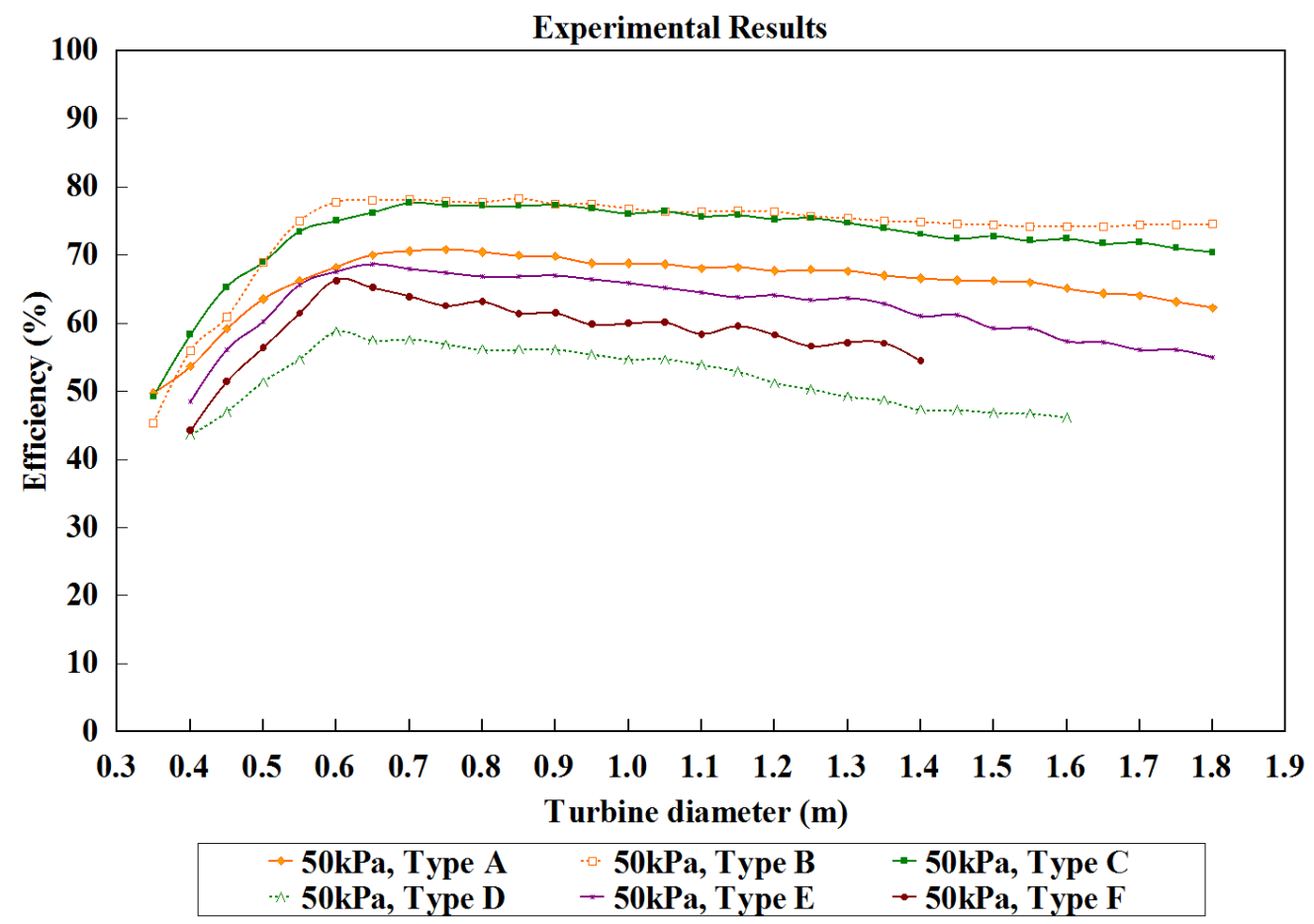

Fig. 13. Efficiency for various types of Z-blade at $5 \mathrm{~m}$ water head

Theoretically, as shown in Eq. (11), the rotor's angular speed is highly influenced by the component of, $\left(\frac{\dot{m}}{\rho A}\right)^{2}$ which consists of the water flow rate and total nozzle exit area provided that the turbine diameter and water head are fixed. In addition, the mass flow rate increases towards bigger nozzle diameter. However, the component $\left(\frac{\dot{m}}{\rho A}\right)^{2}$ does not always increase with bigger nozzle sizes. 
For instance, at $5 \mathrm{~m}$ static water head, a turbine with Type A operates at $2.41 \mathrm{~L} / \mathrm{s}$ water flow rate, thus, the calculated $\left(\frac{\dot{m}}{\rho A}\right)^{2}$ is 258.14 . For Type $B$ turbine, with maximum water flow rate $1.77 \mathrm{~L} / \mathrm{s}$, the calculated $\left(\frac{\dot{m}}{\rho A}\right)^{2}$ is 313.29. For Type $\mathrm{C}$ turbine with maximum water flow rate $1.0 \mathrm{~L} / \mathrm{s}$, the calculated $\left(\frac{\dot{\mathrm{m}}}{\rho A}\right)^{2}$ is 307.79. All these values prove that the $\left(\frac{\dot{\mathrm{m}}}{\rho A}\right)^{2}$ was not increased significantly, even though the nozzle size is increased. As mentioned previously, this is the reason where the rotational speed does not necessarily increase with the increase of nozzle diameter. Due to this fact, mechanical power and efficiency will also follow the pattern of the component $\left(\frac{\dot{m}}{\rho A}\right)^{2}$, where these two parameters are not increased even though the nozzle is increased. In circumstances, the mass flow rate remained the main parameter to determine the performance of a Z-blade when the nozzle exit area remained unchanged.

\section{Conclusion}

This article discusses the theoretical and experimental performance characteristics of Z-blade reaction typed water turbines. Based on parametric analysis via governing equations and experimental outcome, efforts were made to demonstrate that the nozzle exit area has a dynamic reaction to the mass flow rate, angular speed, power output and efficiency. The length of turbine diameter and nozzle exit area has important impacts on turbine performance, especially on the highwater head. Except for the magnitude of the curves, the curve patterns for rotary speed, water flow rates, mechanical power, and efficiency are identical when the turbine diameter and nozzle exit area are varied.

According to the experimental results, the performance of $0.025 \mathrm{~m}$ blade was better compared to $0.015 \mathrm{~m}$ blade. Meanwhile, the performance of both pipe sizes increased when the operational water head was increased. Furthermore, it was observed that the pattern of the measured performance curves for both sizes of the pipe is almost similar. It is worth noting that the larger the nominal diameter pipe, the greater the maximum rotational speed (optimum diameter) achieved as the amount of water flowing through the turbine is increased.

In overall, the nozzle diameter of $0.008 \mathrm{~m}$ (Type B and Type E) outperforms, resulting in faster rotational speeds, more mechanical power and more efficiency while using less water. Although Zblade turbine type $B$ consumes more water flow rate than turbine type $C$, it is more efficient and produces more mechanical power. As a result, turbine type $\mathrm{B}$ performance indicated that it is the best turbine for water heads of $50 \mathrm{kPa}$ and $40 \mathrm{kPa}$.

To summarise, the overall performance analysis presented in this work specifies that the Z-blade turbine can respond quickly and easily when operating at a very low water head at less than $10 \mathrm{~m}$. Additionally, the reaction typed turbine also has other advantages in terms of its ability to be used in pico-hydro systems with low-head and low-flow water resources.

The pico-hydro system discussed in this paper will be further evaluated in the future to determine its performance in terms of power production at real hydro sites in rural areas. The approach used to survey and identify the hydro site will also be discussed briefly. It's also important to assess the potential of the off-grid battery-based hydropower system to meet local demand.

\section{Acknowledgement}

The authors like to express their gratitude to the Universiti Teknikal Malaysia Melaka for providing laboratory facilities and technical support. 


\section{References}

[1] Basar, M. F., N. A. M. Rais, F. S. M. Hassan, K. A. Ibrahim, and K. Sopian. "Economic Analysis on Design of a Simple Hydraulic Reaction Type Turbine for Low-Head Low-Flow Pico Hydro." International Journal of Innovative Technology and Exploring Engineering 9, no. 2 (2019): 3976-3980. https://doi.org/10.35940/ijitee.b7257.129219

[2] Yaakub, M. Faizal, M. Farriz Basar, F. Hanim Mohd Noh, and Hambali Boejang. "Pico-hydro Electrification from Rainwater's Gravitational Force for Urban Area." Telkomnika 16, no. 3 (2018): 997-1003. https://doi.org/10.12928/telkomnika.v16i3.8076

[3] Adanta, Dendy, Kaprawi Sahim, and Amrifan Saladin Mohruni. "Feasibility Study of PVC Pipes as Vertical Axis Wind Turbines Type Savonius Bucket for Remote Areas Application." International Journal on Energy Conversion (IRECON) 9, no. 2 (2021): 41-47. https://doi.org/10.15866/irecon.v9i2.19270

[4] Date, Abhijit, Ashwin Date, Aliakbar Akbarzadeh, and Firoz Alam. "Examining the potential of split reaction water turbine for ultra-low head hydro resources." Procedia Engineering 49 (2012): $197-204$. https://doi.org/10.1016/i.proeng.2012.10.128

[5] Rais, Nurul Ashikin Mohd, and M. F. Basar. "Pico-Hydro Generation System: Empirical Investigation on a Novel ZBlade Low-Head Low-Flow Water Turbine." International Journal of Renewable Energy Research (IJRER) 11, no. 1 (2021): 108-113.

[6] Belkacem, Safer Nabil, and Abedelhadi Beghidja. "Numerical Investigation of Coaxial Turbulent Jet." International Review of Mechanical Engineering (IREME) 13, no. 2 (2019): 78. https://doi.org/10.15866/ireme.v13i2.16668

[7] Farriz, M. B., H. Boejang, M. Masjuri, M. S. M. Aras, N. H. A. Razik, S. Mate, and K. Sopian. "Evolution of simple reaction type turbines for pico-hydro applications." Jurnal Teknologi 77, no. 32 (2015). https://doi.org/10.11113/jt.v77.6980

[8] Date, Abhijit, Ashwin Date, and Aliakbar Akbarzadeh. "Investigating the potential for using a simple water reaction turbine for power production from low head hydro resources." Energy Conversion and Management 66 (2013): 257-270. https://doi.org/10.1016/j.enconman.2012.09.032

[9] Date, Abhijit. "Low head simple reaction water turbine." School of Aerospace Mechanical and Manufacturing Engineering. RMIT University (2009).

[10] Çelo, Marialis, and Rajmonda Bualoti. "Grid Integration Issues and Possible Solutions Considering the Expansion and Deployment of Hydropower Plants in Albania." International Review of Electrical Engineering (IREE) 15, no. 1 (2020): 80. https://doi.org/10.15866/iree.v15i1.16497

[11] Ababneh, Mohammad Khalil, and Adnan Ishtay. "A New Hydro-Compressed Air Storage System Using RepetitiveControlled Technique." International Review of Mechanical Engineering (IREME) 12, no. 2 (2018): 107. https://doi.org/10.15866/ireme.v12i2.12614

[12] Ebhota, W. S., and P. Y. Tabakov. "The Development of Civil Components of a Small Hydropower System." International Review of Civil Engineering (IRECE) 10, no. 6 (2019): 274. https://doi.org/10.15866/irece.v10i6.16261

[13] Dadfar, Avin, Mohsen Besharat, and Helena Margarida Ramos. "Storage Ponds Application for Flood Control, Hydropower Generation and Water Supply." International Review of Civil Engineering (IRECE) 10, no. 4 (2019): 219. https://doi.org/10.15866/irece.v10i4.17133

[14] Basar, Mohd Farriz, Fatin Syakira Mohd Hassan, Nurul Ashikin Rais, Izzatie Akmal Zulkarnain, and Wan Azani Wan Mustafa. "Performance Analysis of Z-Blade Reaction Type Turbine for Low-Head Low Flowrate Pico Hydro." Journal of Advanced Research in Fluid Mechanics and Thermal Sciences 85, no. 2 (2021): 51-65. https://doi.org/10.37934/arfmts.85.2.5165

[15] Date, Abhijit, and Aliakbar Akbarzadeh. "Design and analysis of a split reaction water turbine." Renewable Energy 35, no. 9 (2010): 1947-1955. https://doi.org/10.1016/j.renene.2010.01.023

[16] Date, Abhijit, Aliakbar Akbarzadeh, and Ashwin Date. "Performance investigation of a simple reaction water turbine for power generation from low head micro hydro resources." Smart Grid and Renewable Energy 3, no. 03 (2012): 239-245. https://doi.org/10.4236/sgre.2012.33033

[17] Camacho, John Alexander, Cristian David Chamorro, and Nayiver Gladys Caicedo. "State of the Art of Teleoperated Energy Harvesting Systems for Small Hydropower Plants." International Review of Electrical Engineering (IREE) 14, no. 3 (2019): 182. https://doi.org/10.15866/iree.v14i3.16542

[18] Towoju, Olumide Adewole, and Felix Adedayo Ishola. "Pros and Cons of Electricity Generation from Different Available Sources." International Review of Mechanical Engineering (IREME) 14, no. 6 (2020): 374-380. https://doi.org/10.15866/ireme.v14i6.19104

[19] Date, Abhijit, and Aliakbar Akbarzadeh. "Design and cost analysis of low head simple reaction hydro turbine for remote area power supply." Renewable Energy 34, no. 2 (2009): $409-415$. https://doi.org/10.1016/i.renene.2008.05.012 
[20] Onlam, Arun, Daranpob Yodphet, Rongrit Chatthaworn, Chayada Surawanitkun, Apirat Siritaratiwat, and Pirat Khunkitti. "Power Loss Reduction in Small-Scale Electrical Distribution System Using Adaptive Shuffled Frog Leaping Algorithm." International Journal on Energy Conversion (IRECON) 7, no. 1 (2019): 12. https://doi.org/10.15866/irecon.v7i1.16213 